\title{
現代的無綫电电子学"
}

\section{B.A. 科捷里尼可夫}

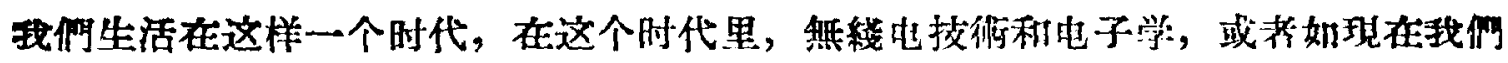

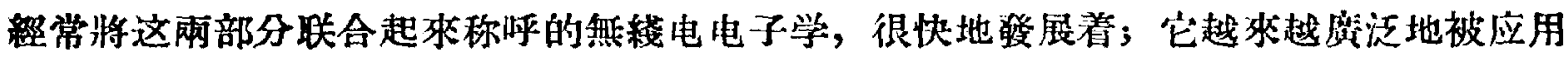
在工業、交化、科学、通信、运輸和國防技県上。在苏联，从战乎前的 1910 年到 1955 年，虽然中間有由于战孚所造成的損失，但無綫电工業的店品增長到 10.8 倍，而苏联整 个工業品在同一时期附則僅增長到 3 倍。在資本主义國家里，低糐电电子学得到最大 發展的是在美國。在 1955 年, 美國然綫电电子学方面工業的洨品雨倍于 1950 年的產品。 在同一时期，國家的总变品只堆長了 $35 \%$ 。現在，从不同数据看來（顯然，这慗决定于 怎样地來看整綫电电子学), 在美國有 50 万到 160 万人从事然綫电电子学方面的工作, 这里面还不包括从事为無挠电电子学生原料和牛成品的工業。如啉包括这些工業的人 数，那末上述数字大約还要加一倍。

無綫电电子学技術的增長，可以用电子真空器件道品的增長很好地表示浽來。在苏

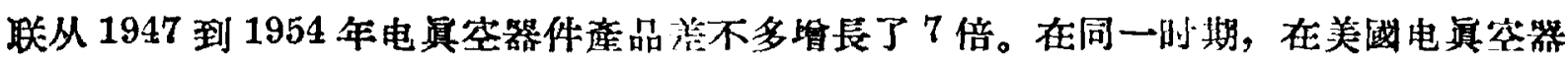

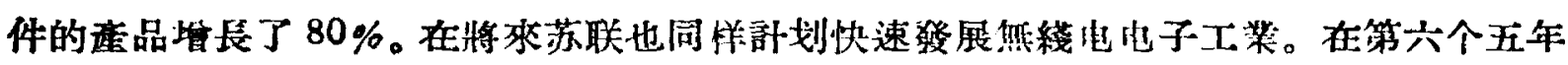

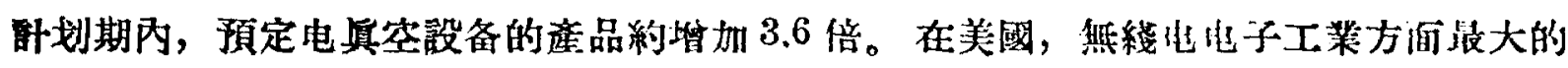
一个公司 RCA, 預定到 1965 年（就是三个五年以后）品特加到 1950 年的 3 倍。按照

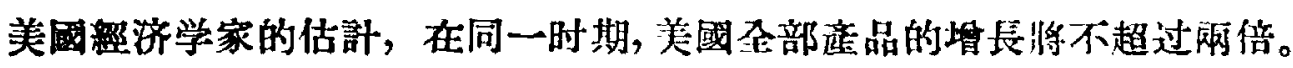

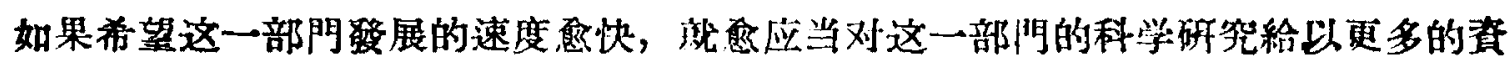
金，加以更大的注意。美國在 1955 到 1950 年的預算年度，在無綫电电子学力湎的研究 预計用 45 憶美元, 这美不多是整个國家研究䩀用的 $25 \%$ 。在荕联, 特別是最近几年, 当我們的無䋐电工業水本接近于最發达的資本主义國家的时候, 当我倗应当赶上㚘超过 这些國家的水本的时候，我郡对于無綫电电子学方面的研究給子丁很大的注意。

这里我想談一部現今無綫电电子学面前的問題, 也就是科学家們在这領域里所从东 研究的問題。

\section{一 無綫电波的傳播䦜題}

在無綫电技術中無綫电信号的傳播䦗題永远是具有重要意义的。如果研究一下它的

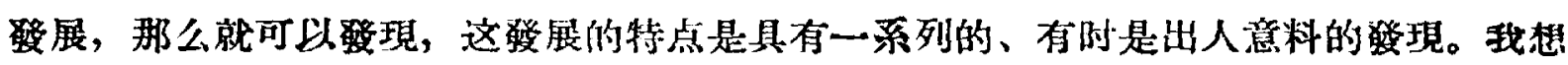
隶回燱一下这个問題的歷史。

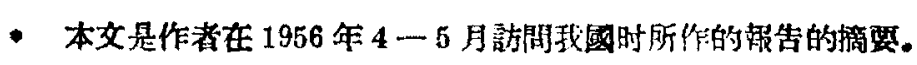




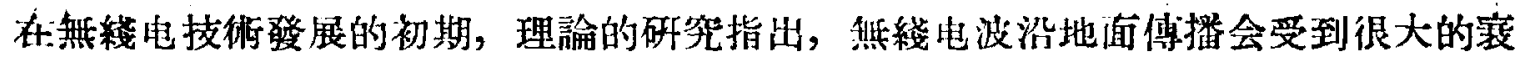

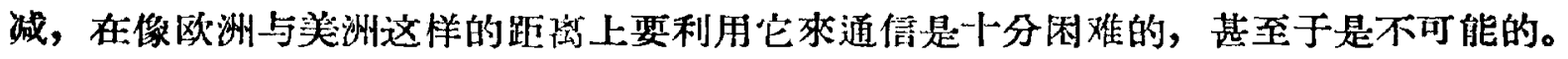

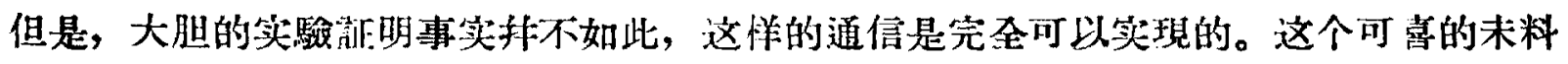

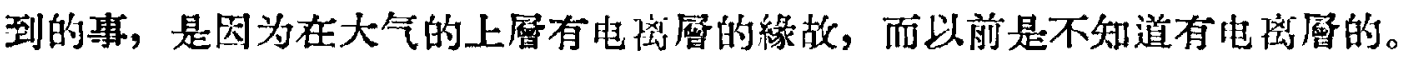

此后, 理論和实驗指出, 同样功率的無綫电台, 它的渡長越長就越適合于远距离通 信, 因此, 長波被認为是最有价做的, 而認为短设的价值不大, 于是就把短波分給了無 馢电爱好者。出人意料的是, 短波（波長为几十米的电波）恰好是最適宜于远距离傳彪 信号, 而現在的远距瓷通信也基本上是利用短波。原爽的錯誤应該这样來解稡：笑驗作 得不够充分, 在这个問題的研究过程中, 当接收机不能够收到信号付, 没有再增加接收 机和电台的距缡。这样当然就不能够發現在更远的距离上接收又重新成为可能了。以前 的理諭由于没有关于电离厤的充分資料，也就不佂指出这种現像。

現在我們蜜泛地应用着超短波（也就是波長短于 10 米的电波）。超短波的所以被廣 泛应用一方面是因为更長的波段上的負荷已經太重, 另一方面是因为现代的無綫电測位 和电視只有利用这一波段才可能实現。但是，超短波在地平綫外傅播时䇏減很大（个別 不常見的情况除外)。这佯就不得不利用無綫电接力綫路轵傅播超短波信号。在無䋐电接

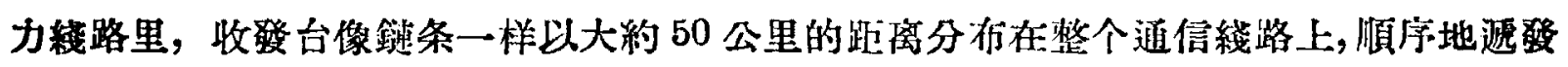
信号。这种䢙信綫路得到了很廣泛的应用, 因为利用它可以傅送上百、上干的电話和电 报倍号, 也可以傅揆电視。

現在，实驗指出，超短波在地本綫外傳播时吱然毫减很大，但比所们計的裹减值却 要小很多倍 (小几千甚或小几百万倍), 因此, 在發射机功率和天綫都㫦大附忤况下，在

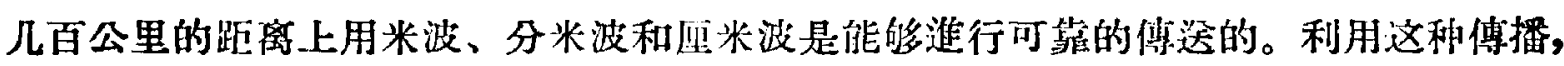

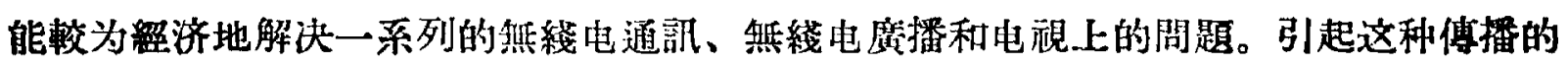
原因到現在为止还不十分清楚，关于这点，現在存在有几利理論。

依我來看，这种現缘的最令人可能相信的原因是: 大一的折射率永远存在着不均匀 性, 而無馢电波在大气里傅播时受到散射。为了廣泛地使用超短没的远距畦傅播，必須 很好地研究这个問題。在研究这个問題时, 必須有气像学家参加。如果有数学方面猄家 参加也是有很大好处的，因为还沒有一个同时考虑到大气的折射率随滈度的变化、大气 里偶然的不均匀度、土地的偶然的不本坦性等等的关于無馢电波沿地面傅播的理論。

用超短波在远距离上傅送信号的另一科現在可以栲点使用的办法是利用波等管，也 就是金屬管，在金屬管里，电波依次由各个管罋反射，而沿着曲折的 “ $Z^{n}$ 字形前進。

这种傳选信号的形式有很大的可能性被利用, 因为它能够傮避几千或几万兆赫 $\left(10^{9}-10^{10}\right.$ 周/秒) 的寬频带。这也就可以使我們僅僅放設一次管子, 而用爽同时傅远 几百个电視節目。这样, 波涪管綫路的傅迕能力要比現代的無綫电接力綫路的傮迕能力 大几百倍。而它們的成本造价, 㙷然却仍是彼此差不多。

要解决这个問題, 同样也需要数学家的帮助, 因为这里將要处理的是复䌖的电动力 学問題, 它涉及到的不只是沿国杜形而且是沿各利形狀管子（势形管、国錐形管、上有 切䋖的管等等) 的电洨傅播問題。在这个䦓題上，也需要制造管子的工㙯师和防止管子 㰌触的物理化学方面桨家的帮助。 


\section{二 無綫电波可用頻帶的展寛}

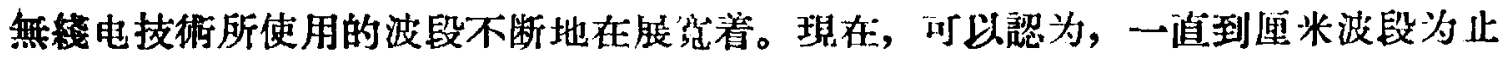
的各波段，包括厘米波段本身，我們都学㨋得不坏，下一个就輪到了妻米波段了。

下边的表可以近似地表示出波段展賀的情况。

$\begin{array}{ll}1920 \text { 年 } & \text { 波長>100 米 } \\ 1930 \text { 年 } & \text { 波長>10 米 } \\ 1940 \text { 年 } & \text { 波長> } 1 \text { 米 } \\ 1950 \text { 年 } & \text { 波長> } 1 \text { 厘米 }\end{array}$

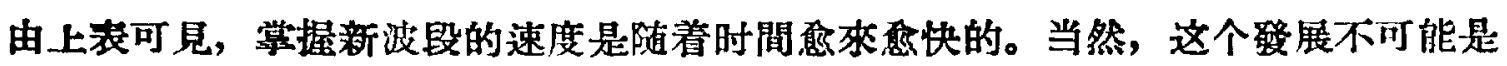

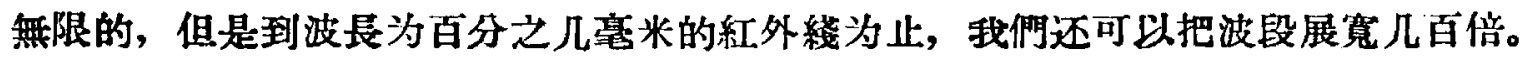

毫米波波段的掌握預示着什么呢? 到現在为止，每学握了一个新波段，就都得到了 新的結果。例如, 短波段（波辰为几十米的电波）的掌握使我們可上用較小的功率徘非 常远的距离傐送無綫电信号。

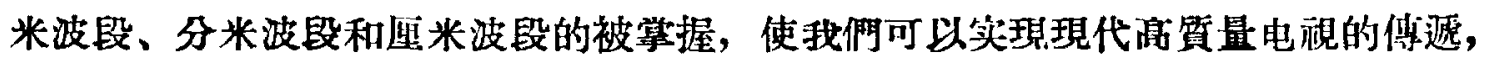

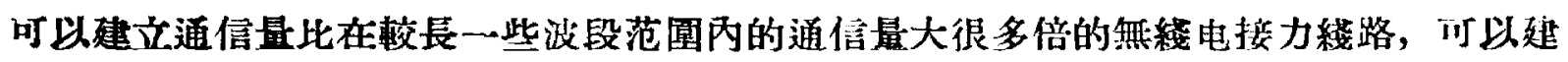
立現代的射电天文学、無綫电頻部学。此外, 还出現了一和可能性, 就是可以建立許多 个在距离不远的地方工作的無綫电台，而拌不使旧的波段变得更拥挤。

如初步的計算和实驗所証明，沿波導管在远距离上佂愉無綫电信号，最適用的是毫 米浪, 这个波段地可以有力地促進無綫电测位向前發展, 而使它的作用接近于無綫电电 視，这就是話我們將不僅能够测定出某一个目标物的位谓，同付还能的制淤出这一目标

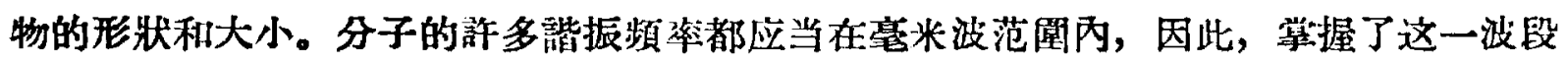

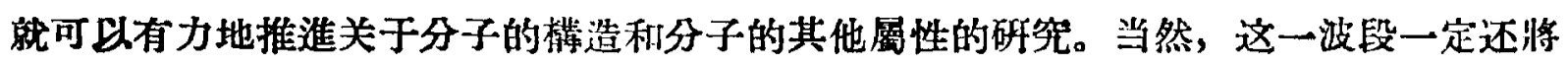
有許多其他用途，关于这些，目前还很难諠。

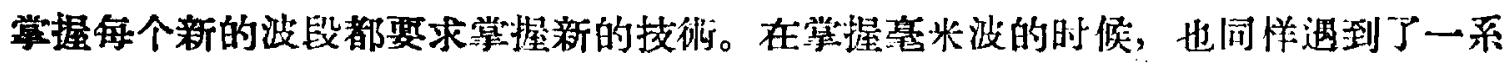
列的困难。当然, 在原則上, 这些困难可以朵用相应維小所有設备或霍件的人叮的办法 來解决, 但是, 同时保桩需件制造的必要精确度是很困难的, 此外。这样作的結果将会 顯著地减少钤备所能給出的功率。为了克服这些倣难, 顯然应当尋求新的原則。在这方

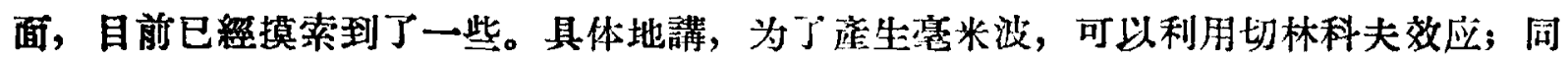

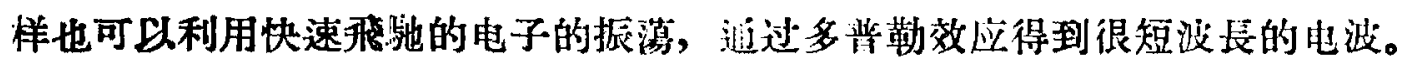

利用分子固有振藻的發射, 就有了很大的叮能性在岒米波段的短没部分以及在毫米

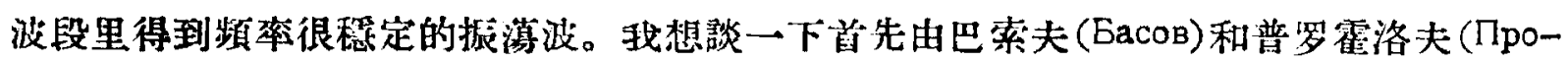
хоров)提出来的分子振深器。

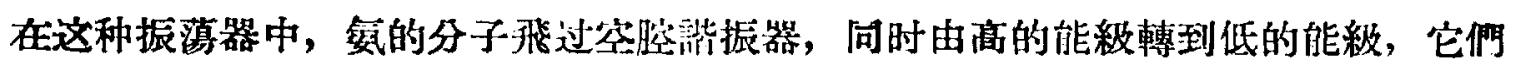
射出波長为 1.25 埋米的振薄波，这个波長是由分子性質所决定的。这和振落波激淤空 凌諧振器, 于是空腔諧振器就开始使以后的分子的發射同步。这样一桃, 各个分子就同 相地射振落波。为了使高能級分子所登射出的振薄波不为低能級分子所吸收，要在它 們進入空腔諧振器之前, 把它們分离圷, 即讓它們先飛过有不均匀电場的电容器。这利 
电容器使具有低能級的分子偏到一边去。所談的这种分子振落器的特点, 就景利用同步

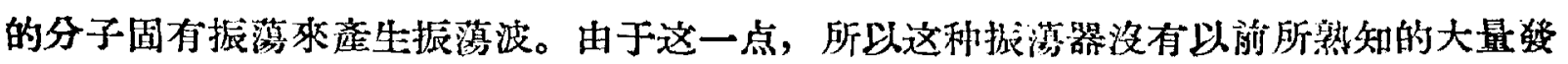
射的振薄器所具有的那一些缺点。在那些振葓器中, 許多振子都互不相火地發射振薄波, 因此相位是各不相同的。

我指出了產生非常短的無綫电波的几个方法。在将來，这些方法北竟有多大的適朋 性，以及还將要有些什么方法被提出來，还有待于实踐桃柧明。

为了开展篦米波方面的工作, 电动力学方面必須要有物理学和数学方面尃家来参加。

\section{三 信息傳藶理論}

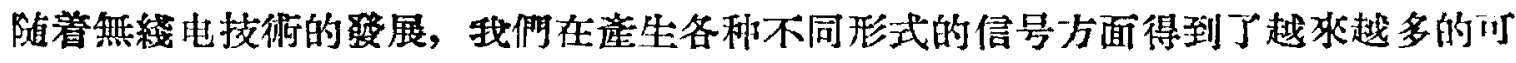
能性。除了幅調制以外，出現了頻調制、相調制、各种㥟冲調制和組合式調制等系統。 現有的信号，其类別形式如此之多，以致如果不利用某种一般的方法，那枺，要研究它 㑚就非常困难。同时，对于抗影响的研究更变得格外复雜化，因为对每种等的信号都 必須分析几种不同的接收方法。

最佳的（或者理想的）接收机的概念和潜在抗于扰度的概仝的提出，是一个巨大的 淮步。理想的然馢电接收机是指在給定的信号和干扰情况下，信号接收具存留小尖惑的 接收机。对于理想接收机來說, 所得到的失基将是可能最小的矢基。它表示着在給定信 号和干扰情况下最大可能达到的抗干扰度, 也斯是潜在的抗干抗度。实际的接收机中, 抗干扰度叮能达到这个数值, 但是不可能超过它。

我們引用了潜在讪抗于扰度这一概念，这样就使分析籣化，因为我們将不必分別去 考慮在各种类型接收机情况下的信号失兵, 而只姴估計潜在的抗干扰度就的了。

这問題要根据干把形式來考慮。

單位时間內到达的于扰豚冲的数目很多时, 由这些脉冲引起的非穞定过程在接收机 中相互重叠得很厉害, 以致有可能对它們采用几率論的極限定理。这样, 就大大优例究 簡化。此种类型于扰一般叫做起伏干扰, 又叫做白噪声或高斯噪声。某几种然型的天电

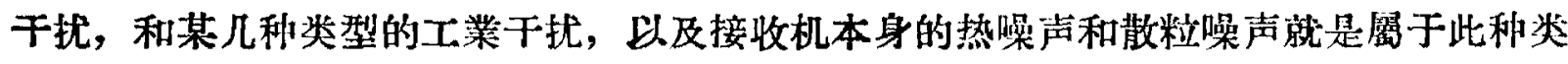
型的干扰。在超短没范固，主要就是这种类型的干扰。琴在，对于这种类型于扰情况下 信号傳遞的研究, 正全面地向前淮展。

过去对这些干抗所作的研究工作告訴我們，为傅晞信号所需要的最害此带应該由我

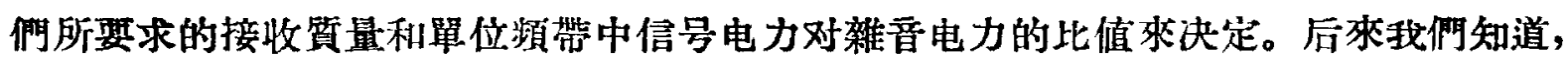
在电話傅輸上完全保持語言的分辩率，科在䋐路中仍然保持目前的信号对干扰的电力比 的情况下，还可上把信号所占用的頻帶維小几百倍; 在电峴傅輸上，还可以縮小几十倍; 在电报傳輸上, 稍微再加宽一下它的頻帶（增加百分之几十）, 即使是在比校坏的（这是 指信号对干扰的比值說的)綫路里, 也可上使信号的失悬的几率达到任何小的程度。

各位当然很清楚，如果能够在已有的綫路里傳輸更多更多的电話、电攽和电傅基， 而电报傅輸实际上又可以不失真的話, 这有着多么大的意义。

然而, 整实現理諭上所指出的上面那些可能性, 还需要進行很大的工作。問題是在 于, 为接收信号所拟定的理諭綫路虽然玎以提供以上所說的可能性，但目前由于过于复

9 月是 科学通报 
雜累慗，在实际上还不能实現。但可能性是有的，应当为使其实現而工作。

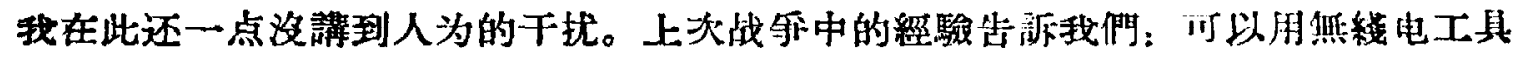
制造出这些人为干扰。研究怎样克服人为干扰是有很大的國防意义的。

关于这一方面的研究工作，大部分都是屬于几率理論范圄的。

我詳細地談过了無䋨电电子学方面三个大的科学問題, 当然科沒有包括科学研究机 棈和高等学格中应当从事研究的所有的有关無馢电电子学的䦓題。

在創造出將有密诖用途的彩色电視系統方面，应当淮行巨大的科学研究工作。

在天綫方面，对实际有很大意义的工作是讙电波的射除在所希望的方向外，在其 他方向都尽可能地减少。对于缄少無綫电电波彼此之間以及和其他設备之間的于抗爽

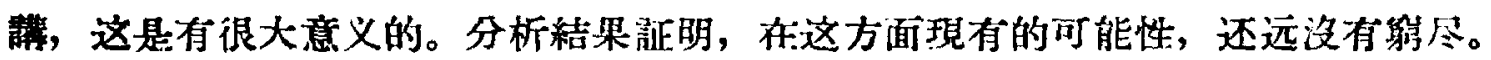

利用鉄涂氧磁物到天綫和其他的采統里，叮能解决一系列利朋其他方法所不能解决

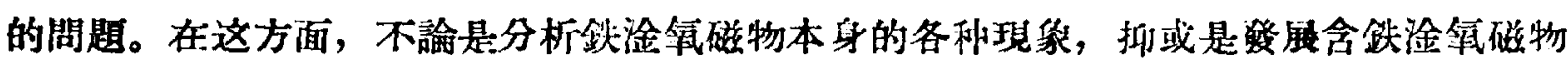
（其磁性是用張量來表示的）的蝶筫的电动力学等等，都是科学上的重要任务。这方鲇 需要物理学家和数学家的帮助。

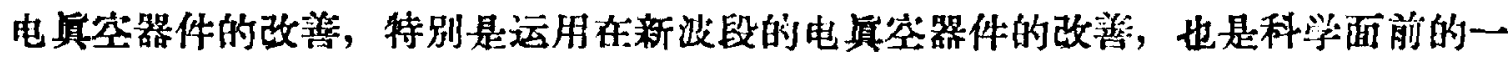
个巨大任务。

往临空中放射电子的陰極是电真空器件中最討肤而又一定得存在的部分。我所䚺討

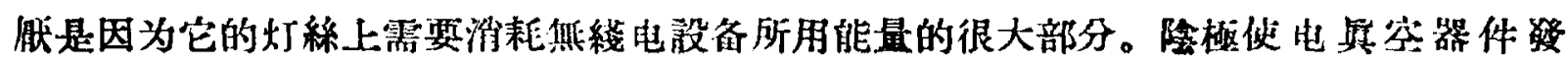

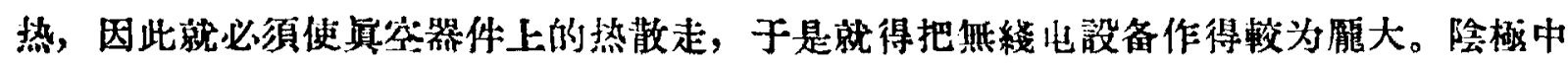

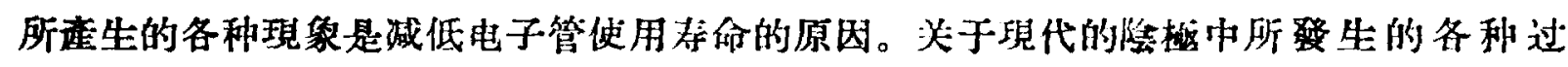
程, 研究得还非常不能, 可以期待, 在这吉面的㤡究工作將一定会大大㘿大陆子管的可 营性和教爽。物理学家应当研究这个題日。

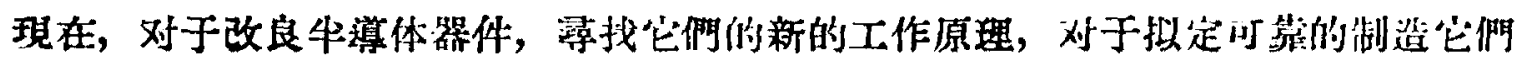
的工裁方法, 对于研究使用半導体器件的䋐路等, 到处都在進行巨大的工作。像各位已 知知道的, 由于牛导体器件的工作时間長久、体皘小和消耗的电能小，牛導体器作的使 用在無绕电电子学中又开辟了一些新的远景。

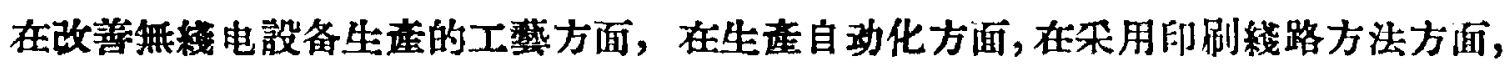
在察找新的材料和零件方面，也应当注行巨大的研究工作。

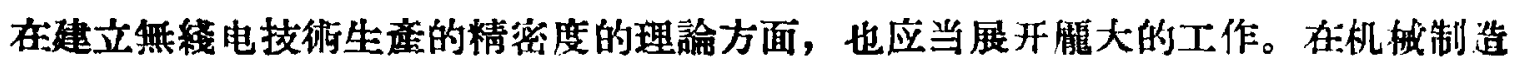

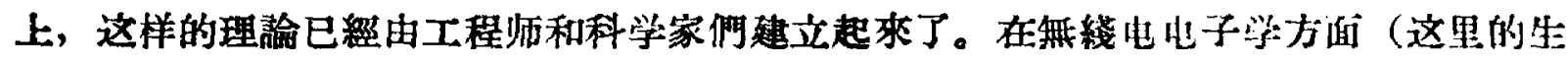

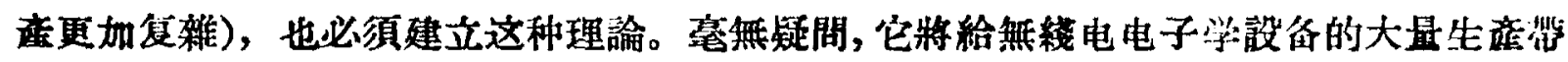
來很大的好处，而这恰好是我們國家非常关心的事情。

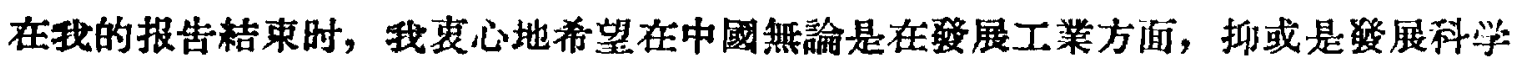

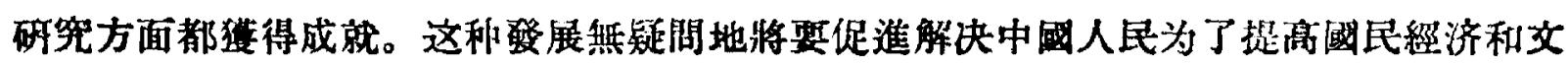
化水平而提出的巨大任务。

〔陈成全知法成楊行明穓〕 